\title{
Nectria pseudotrichia, como Agente Causal de Cancro de Ramos, Ocorrendo em Pereira Japonesa no Brasil
}

\author{
Walter F.B ecker \\ EPAGRI-Estação Experimental de Caçador, Cx. Postal 591, 89500-000, Caçador, SC, e-mail: wbecker@epagri.rct-sc.br
}

(Aceito para publicação em 06/09/2002)

\begin{abstract}
Nectria pseudotrichia, as the causal agent of stem canker, occurring on japanese pear in Brazil

Nectria pseudotrichia is reported for the first time in

Brazil causing stem canker on Pyrus pirifolia. The pathogenicity of the fungus was confirmed by artificial inoculations.
\end{abstract}

Em levantamento de doenças que ocorrem na pereira japonesa [Pyrus pyrifolia (Burm.) Nakai] realizados a partir de 1998, nos municípios catarinenses de Frei Rogério, Otacílio Costa e Caçador, Palmas (PR) e São Miguel Arcanjo (SP) foi verificada a ocorrência de cancros com coloração pardo-avermelhada e depressão da epiderme com seca dos ramos. Durante os períodos de alta umidade foi possível constatar a presença de sinêmios de cor alaranjada, distribuídos isoladamente ou em grupos, sobre a área infectada (Figura 1).

Fragmentos do tecido de ramos infectados e após assepsia foram colocados em meio de cultura BDA onde desenvolveu micélio abundante de coloração rosa alaranjada. O teste de patogenicidade foi realizado em ramos de plantas envasadas, de três anos, e em ramos cortados com 200 mm de comprimento, das cvs. Housui e Nijisseiki. Na parte central dos ramos foi feito um ferimento em forma de "V" com $6 \mathrm{~mm}$ de comprimento descolando-se a epiderme. Discos de $3 \mathrm{~mm}$ de diâmetro contendo meio de cultura e crescimento micelial foram transferidos para este ferimento e em seguida vedado com algodão úmido e tira plástica. Nas plantas envasadas foram inoculados dois ramos por planta e avaliados 45 dias após medindo-se a extensão do cancro. Dez ramos por cultivar foram igualmente inoculados e incubados durante 11 dias em câmara de crescimento tipo B.O.D a $25^{\circ} \mathrm{C}$. Como controle usaram-se ramos inoculados apenas com o meio BDA, tanto nas plantas envasadas como nos ramos cortados.

Na cv. Nijisseiki, em vasos, o desenvolvimento da lesão atingiu $11 \mathrm{~mm}$ enquanto na cv. Housui atingiu 47,2 mm. Nesta cultivar houve a formação de sinêmios alaranjados nos cancros desenvolvidos a partir da inoculação artificial. Nos ramos cortados, houve maior desenvolvimento da lesão em ramos da cv. Housui. Nesta cultivar, $60 \%$ dos ramos estavam completamente tomados pela doença com média de extensão do cancro de $130,9 \mathrm{~mm}$. Na cv. Nijisseiki o cancro se estendeu por $25,5 \mathrm{~mm}$. Não houve desenvolvimento de sintomas nos ramos destacados e de plantas vivas usados como controle. Dos ramos doentes o fungo foi reisolado, completando-se os postulados de Koch. Os conídios obtidos a partir de sinêmios produzidos nos cancros inoculados artificialmente foram idênticos aos encontrados naturalmente, sendo hialinos, unicelulares, com uma das extremidades mais afinada e tendo, como média de 100 conídios mensurados, as dimensões de 8,58 $\mu \mathrm{m}(6-11 \mu \mathrm{m})$ x 4,45 $\mu \mathrm{m}(3,2-5 \mu \mathrm{m})$. O fungo, inicialmente branco, produziu abundante micélio rosa alaranjado em meio de BDA. Não foi observada a formação completa de sinêmios ou presença de esporos neste meio de cultura. Nos ramos artificial ou naturalmente infetados foi encontrada apenas a forma imperfeita do fungo. $\mathrm{O}$ fungo (isolado $\mathrm{CNH}-2$ ) foi enviado para o serviço de identificação do CABI Bioscience, Egham, UK e confirmado pelo Dr. D. Brayford como sendo Nectria pseudotrichia Berk. \& M. A Curtis cujo anamorfo corresponde a Tubercularia lateritia (Berk.) Seifert, sendo depositado com o código IMI 388752. Encontra-se distribuído principalmente em regiões pan-tropicais e subtropicais, incluindo o Brasil (Rossman et al. Stud. Mycol. 42:151-152, 1999). Este é primeiro caso $N$. pseudotrichia causando danos em pereira japonesa no Brasil e, provavelmente, no mundo.

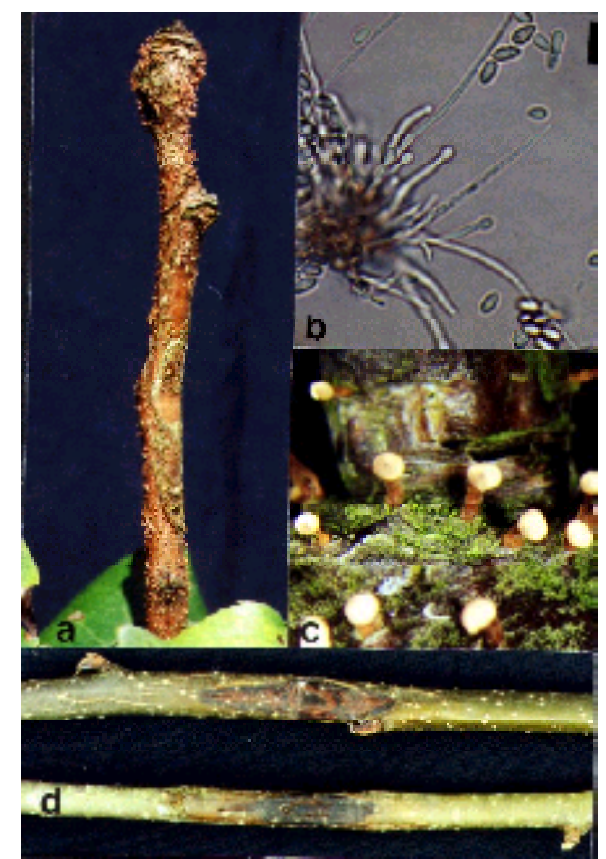

FIG. 1 - (a) Sintomas do cancro em pereira japonesa (Pyrus pyrifolia) cv. Nijisseiki; (b) Conidióforo e conídios de (Tubercularia lateritia); (c) Sinêmios alaranjados no cancro; (d) Inoculação artificial em ramos (cv. Housui). (barra = $10 \mu \mathrm{m}$ ). 